\title{
FUNDAMENTOS DE UM PROGRAMA DE AVALIAÇÃO EDUCACIONAL'
}

Tudo aquilo que sei do mundo, mesmo por ciência, eu o sei a partir de uma visão minha ou de uma experiência do mundo sem a qual os símbolos da ciência não poderiam dizer nada. Todo o universo da ciência é construído sobre o mundo vivido,

e se queremos pensar a própria ciência com rigor, apreciar exatamente seu sentido e seu alcance, precisamos primeiramente despertar essa experiência do mundo da qual ela é a expressão segunda. A ciência não tem e não terá jamais o mesmo sentido de ser que o mundo percebido, pela simples razão de que ela é uma determinação ou uma explicação dele.

1 Artigo publicado na revista Estudos em Avaliação Educacional, n. 28, p. 33-37, jul./dez. 2003.

2 MERLEAU-PONTY Maurice. Fenomenologia da percepção. 2a ed. São Paulo: Martins Fontes, 1999. p. 3-6 [Tradução de Carlos Alberto Ribeiro de Moura].
As reflexões sobre avaliação, ora registradas, decorreram de experiências pessoais a partir de 1962 e se expandiram após 1969, compreendendo a publicação de livros e a elaboração de artigos, 
especialmente os publicados em Educação e Seleção (1980-1989) e em Estudos em Avaliação Educacional (1990-2003), ambas edições da Fundação Carlos Chagas, São Paulo, SP. Contribuíram, também, na atualidade, com bastante intensidade, para a configuração dessas percepções, as discussões e o excelente material gerado pelo Grupo de Trabajo sobre Estándares y Evaluación del Preal, sobre Las políticas de evaluación de logros de aprendizaje en los sistemas educativos de América Latina, no Foro de Discusión $2002^{3}$, de que participaram educadores da Argentina, Brasil, Chile, Colômbia, Costa Rica, Equador, Estados Unidos, Guatemala, Honduras, México, Nicarágua e Peru . As reflexões aqui consignadas procuram identificar aspectos da ação de avaliar, no conjunto das práticas educacionais, e esperam levar a outros pensares capazes de uma definição dos marcos fundamentais de uma política de avaliação no sistema educacional brasileiro.

Os elementos levantados nos vários tipos de avaliação - seja de sala de aula ou de sistemas - devem ser analisados por professores e técnicos especializados nas várias áreas curriculares, a fim de que sejam incorporados ao planejamento escolar e contribuam para o processo educacional. A avaliação não é um valor em si e não deve ficar restrita a um simples rito da burocracia educacional, necessita integrar-se ao processo de transformação do ensino/aprendizagem e contribuir, desse modo, ativamente, para o processo de transformação dos educandos.

A expressão "cultura da avaliação" integra, atualmente, a constelação de palavras técnicas no âmbito da comunidade educacional e aos poucos se vai tornado verdadeiro lugar comum, quase que simples figura de retórica; no entanto, é preciso que essa expressão se liberte do seu caráter de mero truísmo e se transforme numa efetiva política de ação.

As questões relacionadas ao emprego nem sempre adequado dos instrumentos de medida em avaliação educacional devem ser dimensionadas a fim de que os resultados façam sentido e permitam a orientação das atividades docentes; assim, é importante que se aprofundem estudos ligados à avaliação de processo com o uso de instrumentos referenciados a critério, como peça fundamental das atividades de aprendizagem em sala de aula.

Há que pensar em termos de unificação das várias avaliações em relação aos sistemas educacionais; contudo, é fundamental que cada sistema considere a diversidade do seu espaço 
social, econômico e cultural, a fim de evitar interpretações comprometidas e que comparações intra e entre sistemas não levem a colocações destituídas de valor educacional ou que gerem proposições falaciosas.

Os resultados das avaliações não devem ser usados única e exclusivamente para traduzir um certo desempenho escolar. A sua utilização implica servir de forma positiva na definição de novas políticas públicas, de projetos de implantação e modificação de currículos, de programas de formação continuada dos docentes e, de maneira decisiva, na definição de elementos para a tomada de decisões que visem a provocar um impacto, ou seja, mudanças no pensar e no agir dos integrantes do sistema.

A avaliação educacional não subsiste isoladamente, devendo estar associada a outros programas, destacando-se, inicialmente, o de capacitação docente, em que a área da avaliação deve integrar, necessariamente, o conjunto das atividades que levam à formação de professores em quaisquer dos níveis de ensino; por outro lado, a avaliação precisa estar ligada à pesquisa educacional voltada para a realidade dos problemas educacionais relevantes.

A última década do século XX foi rica de avaliações em larga escala, no âmbito internacional e nacional, neste último caso nos vários níveis da administração governamental; nessa década que se inicia, começo de um novo século, contemplando o passado, devemos nos perguntar: - qual o impacto dessas avaliações? E se não houve efetivamente qualquer tipo de impacto, por mínimo que tenha sido, por que não ocorreu? Avaliação e crítica da avaliação (meta-avaliação) devem coexistir em um projeto educacional bem estruturado.

A avaliação educacional não objetiva subsidiar, exclusivamente, a cúpula administrativa; à avaliação deve seguir-se um trabalho bem planejado de difusão dos resultados e das suas análises, a fim de que a sociedade (interna e externa ao sistema) acompanhe o trabalho institucional e possa julgar o seu mérito, inclusive a eficiência transformadora da sua ação.

A partir do espírito de uma nova cultura da avaliação, além da difusão dos resultados, é necessário que se definam diretrizes sobre como usar, produtivamente, esses resultados na melhoria do processo de uma educação que seja eficiente e consequente, evitando-se, desse modo, que os resultados fiquem restritos a uma adjetivação pouco satisfatória. 
Uma política de estruturação de programas de avaliação não pode ficar restrita ao âmbito da escola, deve, necessariamente, abranger todos os níveis da hierarquia da administração educacional, a partir das Secretarias de Estado, quando for o caso, passando por outros níveis, inclusive técnicos, até chegar à sala de aula e ao professor. A avaliação, consequentemente, não é uma ação isolada, integra toda a comunidade educacional e a própria sociedade.

A definição de uma política de avaliação educacional demanda múltiplas considerações, não se restringindo, apenas, ao domínio do conhecimento e ao seu uso na prática. É preciso considerar que, a par do conhecimento para um futuro desempenho, outras dimensões (sociais, culturais e até mesmo éticas) devem ser necessariamente avaliadas e que o programa envolva aspectos quantitativos e qualitativos, incluindo, se possível, interesses, atitudes e valores.

Ao implementar um programa de avaliação há uma preocupação maior em organizar diferentes equipes para fins diversos: administrar, elaborar manuais, construir instrumentos, elaborar questionários, definir logística, orçar despesas, processar dados, analisar informações, elaborar relatórios; contudo, quase sempre se omite a equipe responsável pela disseminação dos resultados, junto aos órgãos centrais, às escolas, às famílias, criando-se, assim, um vácuo nas comunicações, talvez o responsável maior pela ausência de um efetivo impacto transformador.

Avaliações internas são realizadas pelas unidades do sistema com frequência às vezes modesta, e avaliações externas são promovidas por diferentes órgãos oficiais, muitas vezes com a colaboração de instituições privadas, havendo, entretanto, uma falta de sincronia entre essas avaliações, que não têm uma ação efetiva na melhoria da educação. Após sua aplicação, deixam as avaliações de utilizar o seu "potencial energético", entregando-se a uma verdadeira exaustão, até que novo programa se realize, igualmente sem maiores repercussões.

A avaliação não é uma atividade em abstrato, que se realize, como muitas vezes ocorre na prática, ignorando a diversidade dos currículos e a multiplicidade de metodologias de ensino empregadas por professores com diferentes formações (ou ausência de qualquer formação pedagógica), além de posicionamentos diversos quanto às suas áreas de atuação. 
É importante que as avaliações sejam discutidas por diferentes segmentos sociais e os seus resultados examinados em função da diversidade das características sociais e em relação à proposta política que define as linhas mestras da educação. A ausência dessas preocupações pode comprometer a continuidade dos programas de avaliação.

Um dos problemas a considerar em um programa de avaliação centra-se na capacitação técnica daqueles que se propõem a concretizar o empreendimento. Os "avaliadores" nem sempre dispõem de uma formação especifica, abrangente da complexidade dos diferentes procedimentos avaliativos; executando, desse modo, as suas atividades de maneira amadorística e na base de uma possível experiência pessoal. É o fazer por imitação ou o fazer pela reprodução de práticas tradicionais no ambiente escolar. Há, assim, necessidade, talvez urgentíssima, de formação de quadros técnicos, a partir de pessoas com experiência docente, para que as avaliações tenham prosseguimento e não fiquem restritas a uma existência episódica sem maiores consequências.

Há que pensar nos projetos de avaliação para o ensino básico no que dispõem as Propostas Curriculares Nacionais (PCN), em termos da realidade nacional vivenciada pelos professores. Houve um grande esforço do governo federal, no caso específico do Brasil, em definir, às vezes com excesso de detalhes, o que se propunha para o ensino fundamental e médio. Entretanto, uma pergunta se apresenta de imediato a quem se proponha a analisar o que vem sendo efetivamente realizado: - as avaliações estão realmente centradas nas propostas curriculares? A essa indagação segue-se outra: - as propostas curriculares estão sendo efetivamente seguidas no país? As propostas curriculares deveriam ser os referenciais para as avaliações, que definiriam padrões mínimos de desempenho, mas uma terceira pergunta se apresenta: - não seriam os livros didáticos, na sua diversidade qualitativa, os verdadeiros referenciais não apenas para a avaliação, mas para o próprio ensino?

As instituições educacionais, nos seus diversos níveis, ao detalharem seus programas indicativos das disciplinas que integram o programa curricular, devem, em função dos objetivos institucionais e as características educacionais, culturais e sociais do seu corpo discente, definir, operacionalmente, cada um dos conhecimentos associados às habilidades esperadas, a 
fim de que possam caracterizar o nível de capacidade de cada um e promover a aceleração dos que se acham em déficit com os padrões estabelecidos. Ao mesmo tempo, impõe-se dar ciência da situação aos interessados, inclusive à família, para que participem da atividade docente. É importante que a sociedade saiba a que a escola se propõe, em termos de competências educacionais e sociais necessárias, para a concretização da cidadania.

Os padrões para avaliação devem ser pontos de referência para toda a população e refletir as necessidades dessa população, independentemente de etnia, nível social e econômico, evitando-se discriminações que possam criar diferentes níveis de cidadãos e acentuar ainda mais as desigualdades que marginalizam e estigmatizam os indivíduos. Todos os seres humanos têm condições de realizar diversos tipos de aprendizagem e estruturar novos comportamentos desejáveis, limitando-se a questão, na realidade ao timing de cada um, que varia em função de diferentes contingências, como acentuaram Benjamin Bloom e outros, na definição e estruturação de programas de mastery learning (aprendizagem para o domínio).

A definição de padrões ou parâmetros educacionais condiciona, certamente, o tipo de avaliação a realizar e as características dos instrumentos a empregar nos diversos momentos do processo de aprendizagem que visa a formação e, simultaneamente, a transformação dos alunos. É preciso ressaltar que esses padrões não se devem revestir de um caráter estático de permanência no tempo; ao contrário, devem ser revistos periodicamente, elaborados à luz de experiências, modificados, quando for o caso, e até mesmo suprimidos se não mais corresponderem à realidade socioeducacional e não atenderem às exigências e necessidades da sociedade.

Ainda que a avaliação por critério deva ser norma geral para o ciclo inicial de formação, entre 7 e 14 anos de idade, e instrumentos por norma possam ser usados nas demais fases, inclusive nos cursos de nível superior, ou que se façam combinar em um único instrumento a característica de critério e norma, apesar de seus resultados serem mais complexos de interpretar, queremos crer que, independentemente do aspecto formal dos instrumentos, o importante, nessa fase das considerações ora oferecidas, é chamar a atenção para a necessidade de eliminar o caráter coercitivo/punitivo atribuído à avaliação, que sanciona 
alunos, impondo-lhes reprovações nem sempre justificáveis e, às vezes, de forma indireta, solicitando que os estudantes de baixo desempenho, mesmo acima de um possível média teórica, se afastem "espontaneamente" da instituição para não prejudicar o prestígio que esta possa usufruir na sociedade, diante de um possível futuro fracasso do aluno, especialmente no acesso ao ensino superior. O que realmente importa é que a avaliação tenha um efetivo caráter formativo e represente um plus que faça diferença para melhor na vida do aluno; contudo, para que isso ocorra, é preciso um passo mais amplo no processo de formação continuada dos professores, preparando-os para um agir diverso daquele consagrado pela tradição rotineira.

É necessário que não se superestime a questão da definição de parâmetros e competências desejadas. Ao lado disso, e prioritariamente, é imprescindível que se estruture todo um processo de formação continuada dos professores e do corpo administrativo para que ambos recebam o embasamento necessário à concretização satisfatória de uma tarefa que certamente demanda grandes esforços de planejamento. São conhecidas as deficiências profissionais, sobretudo numa época de pouca valorização do magistério e do pouco atrativo que ele representa para os mais talentosos. Além do mais, ressaltemos a imperiosidade do preparo de material didático adequado a diferentes situações, a fim de superar possíveis desvios ou deficiências de aprendizagem e impedir, assim, que se consolidem situações que mais tarde serão difíceis de reverter.

A avaliação não deve utilizar critérios de classificação das escolas (ranking), segundo o desempenho da instituição, para fins de divulgação e conhecimento público das que poderiam ser consideradas como sendo as melhores, em função dos seus resultados. As possíveis e reduzidas vantagens do ranking no desenvolvimento de uma nova cultura da avaliação acabam por ser superadas por uma problemática bem mais complexa, que é a geração de uma competitividade negativa no interior da instituição. $O$ insucesso em avaliações pode resultar de numerosos fatores (sociais, econômicos e até mesmo culturais, como no caso bem conhecido recentemente de escolas na Inglaterra, após a chamada era Thatcher) e não, necessariamente, de razões pedagógicas associadas à provável ineficiência do magistério. O possível insucesso, caso seja institucional, deve ser objeto de 
pesquisa, análise e discussões dentro da própria instituição, com a participação efetiva e solidária da família, que também integra o processo de avaliação.

Um problema a considerar na implantação de um programa de avaliação educacional centra-se na indagação sobre o que fazer com os resultados obtidos. É preciso considerar, por outro lado, se esses resultados serão realmente compreendidos e absorvidos pelos vários segmentos interessados. Certamente que há necessidade do estabelecimento de relação dialógica entre todos os participantes; por outro lado, deve-se pensar, igualmente, na necessidade da formação de equipes técnicas capazes de analisar os dados, identificar problemas e atentar para as implicações desses mesmos resultados na definição das políticas públicas no campo da educação. A sociedade, por sua vez, deve aperceber-se do significado da avaliação e das lições que pode proporcionar para toda a comunidade, mesmo para os segmentos que mantêm frágeis relações com o mundo da educação.

A avaliação educacional em uma instituição ou em um sistema não deve resultar de decisões individuais, mas refletir um consenso em que diferentes atores - professores, administradores, técnicos, alunos e a própria família, como intérprete da sociedade - procuram definir os objetivos e finalidades da avaliação, além de outros pontos de relevância, como o tipo de instrumento a utilizar, a definição de responsabilidades dos construtores de questões/itens, a estruturação de procedimentos logísticos para a sua aplicação, a escolha de um tipo de escore ou nota que faça sentido para o grupo avaliado e para a própria sociedade, além, naturalmente, de definir os parâmetros para a análise dos resultados e estabelecer os grupos responsáveis por sua interpretação; contudo, ainda que tudo isso e outros elementos mais sejam estabelecidos de forma criteriosa, é preciso colocar uma indagação relevante em toda e qualquer avaliação: - o que fazer com os resultados? Essa é uma questão com inúmeras implicações, que precisam ser consideradas e amplamente discutidas, a fim de evitar que os dados levantados não sejam condenados ao silêncio de um arquivo morto.

Uma questão que merece ser objeto de reflexão consiste na relação entre o professor e o processo de avaliação. Qual o uso que os professores fazem dos resultados das múltiplas avaliações a que seus alunos são expostos durante sucessivos anos letivos? 
É necessário sempre pensar na avaliação no contexto de um processo formativo: - a avaliação para orientar os procedimentos docentes; a avaliação para sugerir novas estratégias eficientes de ensino que levem a uma aprendizagem que seja relevante para o aluno como pessoa humana; a avaliação como um fator de orientação de todo o processo docente, envolvendo não apenas conhecimentos, mas incluindo o despertar de novos interesses e a formação de valores; a avaliação como uma ponte que une professor e aluno visando a um processo interativo gerador de novas aprendizagens; a avaliação como fator capaz de gerar elementos que facilitem a superação dos problemas curriculares e que muitas vezes decorrem de conflitos entre a realidade da escola e o contexto sociocultural em que a mesma se situa. A avaliação, enfim, deve ser um diálogo de todo o sistema com a sociedade e do qual o professor participa, mostrando os resultados do seu trabalho, inclusive reconhecendo possíveis erros, mas, ao mesmo tempo, procurando apresentar novas ideias para que a escola se revele uma instituição criativa que consegue superar os obstáculos da burocracia que muitas vezes a sufoca e envolve todo o sistema.

Existe uma necessidade imperativa de que sejam definidos padrões nacionais e regionais que funcionem como referenciais orientadores para os diferentes tipos de avaliação; entretanto, é necessário que esses padrões ou parâmetros não ignorem o caráter vertiginoso das modificações que os conhecimentos sofrem a fim de que a escola não seja reprodutora de elementos obsoletos. Ainda que a escola muitas vezes seja agência revestida de grande conservadorismo, não pode ignorar as mudanças que ocorrem nas várias dimensões da sociedade e permanecer apegada a padrões rígidos, inclusive quanto a procedimentos avaliativos. Precisam ser geradas novas formas de avaliar - o que demandará espírito criativo dos educadores -, combinando elementos quantitativos e qualitativos, com maior destaque para esses últimos, mas suplantando a dicotomia a que se sujeitam os avaliadores, que se restringem a instrumentos referenciados a critérios e a normas. Ressaltemos, contudo, que os padrões antes referidos não devem ser obrigatoriamente consensuais, impondo-se que na sua definição sejam consideradas as diversidades sociais, econômicas e culturais.

As avaliações, além das características normais relacionadas a diversos tipos de validade (conteúdo, preditiva e de construto), 
devem ter, necessariamente, validade consequencial. A expressão pode determinar controvérsias, necessitando, portanto, ser plenamente esclarecida. A validade consequencial não se refere a distinções, prêmios e/ou bônus, e muito menos a rankings e menos ainda a comparações. É fundamental que os resultados das avaliações cheguem aos alunos, aos pais, aos educadores e a toda a comunidade educacional, não devendo ficar restrita apenas aos policy-makers da administração escolar. Os resultados das avaliações têm suas implicações, não podendo ser tratados, assim, como uma contabilidade educacional. A avaliação deve ter, forçosamente, consequências, se pretendemos pensar em termos da consolidação da chamada cultura da avaliação. A consequência a que nos referimos está relacionada a novas formas de pensar e agir, demonstrando, assim, que os resultados de uma avaliação fazem diferença e promovem o crescimento da pessoa como ser humano e membro da sua sociedade. Esta sociedade, por sua vez, não pode ficar distanciada do que ocorre na escola, indiferente à constatação dos resultados apresentados, que devem ser discutidos com racionalidade e definidos os caminhos para uma solução sensata dos problemas que essas avaliações refletem.

Avaliar é um agir que se reveste de complexidade, ainda que quase todos - professores e não-professores - se sintam qualificados para expressar juízos de valor, cerne de todo processo avaliativo. Se ficarmos restritos ao campo educacional, área de maior interesse no caso presente, constatamos que quase todos temos os nossos sistemas ideais de avaliação, mas que nem sempre resistem a uma análise crítica mais aprofundada. A tendência observada é que tendemos a reproduzir processos de avaliação que nos foram transmitidos por antigos professores, durante nossa formação acadêmica. Isso pode significar alguns acertos, mas, na maioria das vezes, defrontamo-nos com desacertos. Por que? A resposta muito possivelmente está relacionada à formação dos professores ou mais exatamente à ausência de formação dos educadores no campo da avaliação. As licenciaturas concentram-se mais nos conteúdos substantivos do currículo das disciplinas, aos quais são acrescentadas algumas informações pedagógicas, sendo a avaliação de uma forma bastante simplista identificada apenas com a verificação da aprendizagem. Impõe-se uma nova orientação do processo de formação dos professores a fim de atualizar a atual geração de educadores e, ao mesmo tempo, criar condições para 
4 DESCARTES, René (1596-1650). Princípios da Filosofia. Portugal: Porto Editora, 1995. Coleção Filosofia Textos. [Introdução e comentários de Isabel Marcelino. Tradução de Isabel Marcelino e Teresa Marcelino.] que futuras gerações tenham consciência de que ensinar, aprender e avaliar constituem um processo interativo contínuo.

A avaliação não pode ignorar as várias dimensões do contexto escolar, tendo em vista a influência que o mesmo tem, e com destaque especial, na definição das diferentes propostas de avaliação, cujo objetivo maior, no final, e sem que paire qualquer dúvida, centra-se na melhoria do proceder educacional. É preciso atentar para o fato de que é nesse momento crítico, e não apenas para o professor ou para o avaliador, que todos os envolvidos na ação educativa fazem diferentes opções sobre como obter informações compreensivas que permitam decisões individualizadas ou outros elementos que possibilitem amplas generalizações sobre os diferentes atores dessa complexa teia que é o ato de ensinar e educar. Além disso, é em função desse contexto em que a avaliação se concretiza que diversas opções precisam ser definidas de uma forma consistente pelo professor/avaliador: - avaliação por critério ou norma; avaliação formativa ou somativa; avaliação interna ou externa entre outras questões igualmente possíveis e relevantes para os procedimentos subsequentes da avaliação. Não se pode deixar de levar em conta que os elementos obtidos por intermédio das avaliações devem ser, necessariamente, interpretados em função do contexto em que foram levantados, o mesmo ocorrendo com a sua disseminação para os diferentes segmentos interessados nesse tipo de conhecimento.

A educação, em razão do momento histórico, social e político, considera seus objetivos e define metas a concretizar, não havendo, destaque-se, um modelo único e geral que sirva a todos os povos e a diferentes culturas. Há um ponto sobre o qual parece haver algum consenso, certo grau de concordância entre educadores dos vários sistemas educacionais: - a educação não visa a proporcionar apenas conhecimento. $O$ processo educacional procura formar, também, outros tipos de saberes: o saber ser, o saber fazer e, especialmente, o saber pensar, que implica, entre outras dimensões, o compreender, o querer, o imaginar e o sentir, como já acentuava Descartes no distante século XVII ${ }^{4}$. E a esses saberes agregam-se, ainda, habilidades, interesses, atitudes e, particularmente, valores. Tudo isso é importante e necessita ser considerado durante a avaliação formativa/contínua. Esse considerar leva-nos a um aspecto da avaliação que é 
fundamental para todos os seres humanos: - a autoavaliação, a capacidade de alunos (e por que não dizer, professores, também) se autoavaliarem, procedimento que leva ao autoconhecimento e demonstra a consciência que o indivíduo tem de si mesmo.

As reflexões anteriormente apresentadas consideram de modo subjacente o contexto brasileiro e a sua experiência, rica em ensinamentos, em decorrência dos inúmeros projetos de avaliação implementados a partir do final dos anos 80 e intensificados nos anos 90, por iniciativa de diferentes áreas administrativas (federais, estaduais e municipais), além de algumas poucas de iniciativa da educação privada. Atualmente, possuímos volumosa soma de dados sobre escolaridade e variáveis socioeconômicas; contudo, precisamos começar a pensar na sua destinação, ainda que tardiamente, tendo em vista a multiplicidade de usuários possíveis. Uma coisa é certa, e reiteramos mais uma vez, os elementos coletados não podem ser de uso exclusivo da burocracia educacional. É impositivo que os muitos interessados existentes manifestem suas visões e a compreensão que têm dos mesmos. Nesse sentido, com o objetivo de analisar a qualidade da educação e seus problemas, é necessário que se realizem workshops, mesas redondas, palestras, debates e outras atividades mais, com a participação de professores, familiares, alunos e diferentes segmentos sociais para que se aquilatem o valor e o significado dos seus resultados, demonstrando, dessa forma, a sua compreensão e identificando, também, os pontos críticos que por ventura se tenham manifestado. A partir das informações coletadas é possível definir projetos de pesquisa sobre aspectos relevantes, fugindo, assim, à replicação de outras investigações e de temas já exaustivamente estudados em pesquisas anteriores ou realizadas em outros contextos diversos da nossa problemática educacional. Além de definir projetos, é importante que se discuta a própria política de avaliação e se tracem novas políticas, além, também, de pensar a sua fundamentação teórica e as estruturas que sustentam essas avaliações. Em todos esses aspectos, é importante que se tente envolver universidades e outros centros de excelência que se ocupam com a questão da qualidade da avaliação.

As avaliações de sistemas levantam um número considerável de informações que nem sempre são tratadas adequadamente. É necessário que se decida a priori o que fazer com os dados, so- 
bretudo porque, tendo em vista o destino escolhido, a decisão tomada vai influenciar de modo considerável o planejamento da própria avaliação. Anteriormente, procuramos dar mais destaque à avaliação formativa, ao desenvolvimento individualizado. A estrutura dessa avaliação não terá as mesmas características de uma avaliação baseada em normas, que consideram o desempenho do conjunto amostral, expresso por estatísticas descritivas. É significativo, por outro lado, que se identifiquem os diversos segmentos da sociedade que utilizarão, com inteligência, conhecimento de causa e bom senso, os elementos informativos da avaliação. Nem sempre os mais interessados dispõem de formação profissional adequada para um trabalho em profundidade e que tenha ressonância na comunidade acadêmica. No caso específico do contexto brasileiro, reconhecemos que há interesse em divulgar resultados e, nesse sentido, relatórios técnicos são publicados, ainda que com uma certa demora; por outro lado, as autoridades educacionais, a fim de acelerar o processo de disseminação das informações, utilizam-se dos vários órgãos da mídia visando a fazer com que os dados cheguem aos vários segmentos sociais. Isso, entretanto, não basta, não é suficiente, quando não se promovem estudos analíticos que identifiquem pontos positivos do ensino/aprendizagem e as defasagens que se constatam, sendo estas bem mais importantes do que aqueles primeiros.

A ação de avaliar sempre provoca reações, muitas das quais com características negativistas, argumentando que apenas aspectos cognitivos são destacados, sem considerar outros aspectos que, por sua natureza, são, muitas vezes, mais importantes do que o simplesmente aprendido. É preciso não esquecer, contudo, que ao avaliar, implicitamente, também se está avaliando algo mais, representado por habilidades, interesses e valores. A avaliação, particularmente a que é realizada em sala de aula, sob responsabilidade direta do professor, é mais importante, sem dúvida, porque não se restringe a um único instrumento, mas resulta, quase sempre, de muitos outros tipos de fazeres, que englobam elementos qualitativos, incluindo entre essas práticas as técnicas de observação. No entanto, a avaliação sistêmica, realizada em grande escala, pressupõe, naturalmente, procedimentos padronizados, não para fins de comparação, como julgam muitos, mas para gerar um quadro isonômico que dê a todos as mesmas condições para demonstrar as capa- 
cidades de cada um por intermédio dos desempenhos específicos que lhes são solicitados. É forçoso reconhecer, contudo, que os procedimentos de avaliação, por mais bem planejados e refinados que sejam os seus instrumentos, nunca oferecem um quadro completo da realidade do ensinar/aprender, pois nunca se conhece a realidade em toda a sua complexidade, assim como, também, por melhores que sejam os indicadores sociais os mesmos não conseguem refletir, com precisão absoluta, a complexidade do mundo social. Sem a avaliação, entretanto, é impossível formar percepções do processo educacional e da influência da ação educativa da escola-família-comunidade-aluno e professor.

É necessária uma definição de vários elementos indispensáveis a uma avaliação que atenda a todos os requisitos técnicos, conforme registro anterior; desse modo, entre essas decisões, todas igualmente prioritárias, cumpre estabelecer se a avaliação será por norma ou por critério. Se for por critério, como seria realmente desejável, temos de imediato um sério problema a solucionar: - qual seria o ponto de corte a ser definido? Por outro lado, mais um problema, igualmente importante, deve ser equacionado: - quais os padrões a serem estabelecidos? A respeito dos critérios é preciso considerar o fato de que esse estabelecimento parte de dados empíricos; portanto, a posteriori, ou, então, a partir da experiência de professores da área e/ou de especialistas no campo da avaliação. É preciso lembrar que, na elaboração de provas referenciadas a critérios, é forçoso abranger amostras representativas de conteúdos e habilidades, que, supostamente, deveriam ser desenvolvidas na escola. Ainda relativamente à definição de critérios, estabelecidos a posteriori, isso não se constituirá em um grande problema se a metodologia empregada for a da Teoria da Resposta ao Item (TRI), conhecida em nosso contexto educacional graças ao seu uso no Sistema de Avaliação do Ensino Básico - Saeb ${ }^{5}$. É bastante conhecido nos meios educacionais que o problema da fixação de padrões gera controvérsias, mas é uma situação que deve ser encarada e examinada, apesar da sua complexidade. A definição de padrões seria em âmbito nacional ou seriam definidos diferentes padrões regionais, considerando que, muitas vezes, a avaliação não possui caráter censitário, sendo amostral, mas abrangendo uma geografia sociocultural bastante diferenciada? Apesar da complexidade do problema, seria reco-

\footnotetext{
5 Seria interessante ler o trabalho de Gregory J. Cizek - Introduction Achievement Testing in U.S. Schools, disponivel em:http://edex. s3-us-west-2.amazonaws.com/ publication/pdfs/cizek_7.pdf, especialmente a discussão sobre testes referenciados a normas e a critério, para maiores esclarecimentos sobre o assunto.
} 
6 LOCKE, John (1632-1704). Ensaios Acerca do Entendimento Humano (1690) - Livro II - As Ideias, Capítulo IX. São Paulo: Nova Cultural, 1999. p.79-80 mendável a definição de padrões de desempenho com suas habilidades em termos nacionais, conforme a amplitude espacial da avaliação. Esses padrões poderiam servir de orientação para professores, especialistas em currículo, administradores e pesquisadores, na definição de seus respectivos planejamentos e, inclusive, no caso de pesquisas sobre aprendizagem e rendimento escolar.

Insistimos, reiteradas vezes, ao longo das presentes considerações, que o documento ora apresentado procura traduzir a nossa percepção sobre o problema da avaliação e seu possível impacto nos sistemas educacionais, refletindo-se, dessa forma, a nossa preocupação com a chamada validade consequencial, o impacto que toda essa sistemática exerce nos sistemas de ensino. É preciso, no trato dessas questões, evitar a implantação de certos parâmetros valorativos: - classificações, bônus para os professores, vantagens para os alunos ou premiações, hierarquização das escolas, entre outros, que, no final, acabam por dicotomizar os sistemas, as escolas e os próprios alunos em duas categorias: os melhores e os piores. Isso determina a perda do espírito de colaboração que deve existir, estabelecendo-se, em oposição, um espírito competitivo entre sistemas, instituições e alunado. É evidente que esse tipo de "consequência" deve ser evitado e superado, quando existe. $\mathrm{O}$ importante é que as propostas de avaliação sejam um reflexo da realidade educacional e que possibilitem o autoconhecimento do sistema e o conhecimento do sistema pela comunidade social, que nele investirá em termos de recursos humanos e materiais. Uma avaliação que tenha validade consequencial pode-se transformar, sem sombra de dúvida, em um processo de certificação de competência.

Ao longo deste trabalho, procuramos pensar sobre os diferentes problemas ligados à avaliação e suas possíveis soluções a fim de que, aos poucos, mas de forma simples e clara, pudéssemos traduzir as nossas percepções, conforme registramos no início do trabalho. É perfeitamente aceitável que, quando refletimos sobre o que se passa em nosso entendimento, acabamos por gerar e, também, adquirir novos conhecimentos, conforme a visão de Locke ${ }^{6}$. A nossa percepção, desse modo, resultou de uma operação ativa e refletiu a ação do nosso pensamento, mostrando o entendimento que temos da avaliação e o significado que lhe atribuímos no processo educacional. 